\title{
EFFECTS OF YUCCA SHIDIGERA EXTRACT ON THE REDUCTION OF AMMONIA CONCENTRATION IN LAKE KOUMOUNDOUROU
}

\author{
Xiaoxi Yu', Elias Dimitriou' ${ }^{1}$ Sarantakos Konstantinos' ${ }^{1}$, Vasiliki Markogianni' ${ }^{1}$, Dorita Politi ${ }^{1}$ \\ 1 Hellenic Centre for Marine Research, Institute of Marine Biological Resources and Inland Waters, $46.7 \mathrm{~km}$ \\ Athens Sounio Ave., 19013 Anavissos Attikis, Greece, e-mail: xiaoxiyu.stream@gmail.com; elias@hcmr.gr; \\ ksarant@hcmr.gr; vmarkogianni@hcmr.gr; doritapoliti@yahoo.gr
}

Received: 2015.06.06 Accepted: 2015.08.31 Published: 2015.10.01

\begin{abstract}
Nitrogen related water pollution in aquatic systems is one of the most common problems encountered worldwide nowadays. Different restoration practices have been tested to eliminate the impacts from eutrophication but no widely applicable methodology has been found until now. Extract of Yucca shidigera has been proved effective in reducing ammonia in livestock industry and aquaculture but have not been yet tested in freshwater ecosystems. In this study, the effects of yucca extract on the reduction of ammonia in Lake Koumoundourou have been investigated. Yucca extract was added at various concentrations to experimental tanks containing lake water and sediment. The results show that yucca extract significantly reduced the concentration of ammonia while other water quality parameters were relatively stable during the experiment, except from dissolved oxygen. The study indicates that yucca extract as a restoration method can be promising but larger scale experiments should be conducted to validate this outcome.
\end{abstract}

Keywords: Yucca shidigera extract, ammonia reduction, lake restoration, water quality, eutrophication.

\section{INTRODUCTION}

Nowadays, many aquatic systems have high level of ammonia due to anthropogenic related pressures, such as urban waste disposal and fertilizer leaching [Camargo and Alonso, 2006]. Ammonia has been considered as "one of the two (the other being chloride) greatest pressures to aquatic life in the immediate vicinity of wastewater outfalls" [Effler et al., 1990]. Ammonia is toxic to aquatic organisms, especially fish, since the metabolism of fish and crustacean can be severely damaged by short term contact with high level of ammonia [Santacruz-Reyes and Chien, 2010a]. Ammonia is also toxic to some nitrification bacteria, inhibiting the nitrification process, which causes further increase of ammonia in the system [Camargo and Alonso, 2006]. Experiments have shown that finfish and crustaceans can be harmed when unionized ammonia concentration is above $0.5 \mathrm{mg} / \mathrm{L}$ [Santacruz-Reyes and Chien, 2010b].
Moreover, ammonia can be converted to nitrite which is also toxic to aquatic species [Lewis and Morris, 1986].

Few chemical means has been found effective to remove ammonia from aquatic systems. Among them, zeolite has been proved capable of removing ammonia and has been applied to freshwater systems for many decades. However, this material becomes ineffective in seawater since high concentration of ions impede its uptake of ammonia [Burgess et al., 2004]. Moreover, bioengineering methods such as constructed wetlands have been recognized as an efficient way to remove ammonia and have been largely used in wastewater treatment. However, this approach requires the availability of extensive land areas and significant financial resources to construct the wetlands [Demin et al., 2002].

In recent decades, a few researches have been dedicated to studying the efficacy of the extract of a desert plant, Yucca shidigera, on reducing am- 
monia concentration in aquaculture and found it promising [Santacruz-Reyes and Chien, 2010a; Santacruz-Reyes and Chien, 2010b; Tidwell et al., 1992]. Yucca extract has also been used as an additive to ruminant diets to control rumen fermentation and to reduce ruminal ammonia concentration [Tekeli et al., 2007]. Although yucca extract has been proved successful in controlling ammonia in animal husbandry and aquaculture, no studies using yucca extract to treat ammoniarich lakes have been conducted.

The concentration of ammonia in Lake Koumoundourou has been elevated to above $3 \mathrm{mg} / \mathrm{L}$, sometimes even up to $6.9 \mathrm{mg} / \mathrm{L}$, due to the high density of birds populations in the lake, decomposition of organic matter and occasional leakage of urban sewage [Hellenic Center for Marine Research, 2011]. This study aims to investigate the effects of yucca extract on reducing ammonia concentration in Lake Koumoundourou.

\section{MATERIAL AND METHODS}

\section{Study site}

Lake Koumoundourou is situated inshore of Elefsis Bay, about $12 \mathrm{~km}$ from Athens. The shoreline perimeter is about $1700 \mathrm{~m}$ and the surface area is approximately $147,000 \mathrm{~m}^{2}$ [Dimitriou et al., 2008]. It is located at an altitude of $1.41 \mathrm{~m}$ above sea level and its mean depth is $1.5 \mathrm{~m}$. The climate of the catchment area is Mediterranean subtropical with a small annual variation of temperature. There is a constant discharge of fresh water on the northwest side of the lake through a submerged spring [Dimitriou et al., 2008]. Together with seawater intrusion and rainfall, it results in a brackish meromictic environment with an average salinity of $10.50 \%$ [Dimitriou et al., 2008].

The study catchment is located in an industrial area, in the periphery of Athens city and therefore, there are many pollution sources that affect water quality of the lake. During the past decades oil spills and leaks from the oil refineries on the southwest side and the military depot on the north side of the lake had formed a thin oil film on the water surface [Koutsomitros et al., 2001]. Leakages from the landfill on the north side of the lake had further contaminated the lake and groundwater in the catchment area [Dimitriou et al., 2008]. During the last decade, several environmental measures and recent relevant legislation have led to the slight improvement of the lake's water quality which is reflected to the re-appearance of a strong biological community in the lake (fish, birds and mocrophytes).

There are about 30,000 gulls, 3,000 starlings and a small amount of other species of birds in Lake Koumoundourou while the density of macrophytes in the lake has been increased significantly during the last 5 years [Hellenic Center for Marine Research, 2011]. Monitoring of nutrient levels in the lake at a monthly basis during the period 2011-2012 indicated elevated levels of ammonia that coincided with the period of bird migration in the lake. Thus, the bird feces and the decomposition of other organic matters have probably contributed to the high level of ammonia in the lake during the aforementioned period [Dimitriou, et al., 2012].

\section{Experimental design and set up}

Twelve fish tanks were set in the hydrochemistry laboratory of the Hellenic Centre for Marine Research (HCMR), and each of them was filled with $5 \mathrm{~L}$ lake water and $1.5 \mathrm{~cm}$ thick sediment collected from Lake Koumoundourou. The extract of Yucca shidigera (referred to as $\mathrm{Yu}$ in the manuscript) is produced by XVET GmbH in Hamburg, Germany (Art. 147730). Ammonium chloride (referred to as Am) was added to create certain levels of ammonia in different Yucca treatments. Six treatments have been prepared with two replications per treatment. Five concentrations $(0$ $\mathrm{ml} / \mathrm{L}, 0.2 \mathrm{ml} / \mathrm{L}, 0.6 \mathrm{ml} / \mathrm{L}, 1 \mathrm{ml} / \mathrm{L}, 2 \mathrm{ml} / \mathrm{L}$ ) of $\mathrm{Yu}$ and three concentrations of $A m(0 \mathrm{mg} / \mathrm{L}, 3 \mathrm{mg} / \mathrm{L}$, $6 \mathrm{mg} / \mathrm{L}$ ) were added in the tanks (Table 1). Each tank was aerated for five minutes using fish tank pump every day during the experiment that was conducted under ambient temperature and light. The initial concentrations of ammonium has been measured and taken into account when adding the extra ammonium chloride solution in order to reach the desired Am concentration. There were also two tanks where nothing was added in order to act as control treatments. Major physicochemical parameters $(\mathrm{pH}$, temperature, conductivity, salinity, dissolved oxygen) were measured with multiparameter instrument (model Hi 9828/4, USA) every 12 hours for 180 hours which was the total duration of the experiment. Water samples $(10 \mathrm{ml})$ were collected from all tanks every 12 hours for 180 hours and analyzed in the lab for ammonia nitrogen $\left(\mathrm{NH}_{4}^{+}-\mathrm{N}\right)$ and nitrate nitrogen $\left(\mathrm{NO}_{3}{ }^{-} \mathrm{N}\right)$ by using a Merck spectrophotometer. 
Table 1. Experimental design for the effects of Yucca extract on removing ammonia in Lake Koumoundourou

\begin{tabular}{|c|c|c|}
\hline Treatment & Yu (ml/L) & $\mathrm{Am}(\mathrm{mg} / \mathrm{L})$ \\
\hline Yu0-Am0 & 0 & 0 \\
\hline Yu1-Am3 & 0.2 & 3 \\
\hline Yu3-Am6 & 0.6 & 6 \\
\hline Yu3-Am0 & 0.6 & 0 \\
\hline Yu5-Am3 & 1 & 3 \\
\hline Yu10-Am6 & 2 & 6 \\
\hline
\end{tabular}

\section{Statistical analysis}

The results of the experiments (Ammonium and Nitrate concentrations as well as all the monitored physicochemical parameters) underwent thorough statistical analyses by using SPSS software. The data were subjected to the analysis of Pearson product-moment correlation and for the variables significantly correlated the linear regression equations were calculated. Moreover, descriptive statistics and graphs indicating the trends of the monitored parameters concentrations along time were estimated. All the results were assessed and discussed in order to conclude the efficiency of using Yucca extract for the minimization of ammonium concentrations in aquatic systems.

\section{RESULTS AND DISCUSSION}

\section{Effects of yucca extract on physicochemical parameters}

During the experiment, the water temperature of all treatments fluctuated slightly around $19^{\circ} \mathrm{C}$, which is close to the ambient temperature of the particular season. The electrical conductivity of all treatments were around $14000 \mu \mathrm{S} / \mathrm{cm}$ which is a typical value for the brackish water of Lake Koumoundourou. The dissolved oxygen levels (DO, $\mathrm{mg} / \mathrm{L}$ ) presented significant variation over time in six different treatments of yucca (from 0.5 to $6.5 \mathrm{mg} / \mathrm{L}$, Figure 1 ).

For the first 24 hours a steep decrease of DO for the treatments Yu3-Am0 and Yu3-Am6 was observed, while a less reduction rate was measured in the treatments Yu5-Am3 and Yu10-Am6 and very little decrease in Yu0-Am0 and Yu1Am3 (Figure 1).

For the time period of 24 until 60 hours the treatments Yu3-Am6, Yu3-Am0, Yu5-Am6, Yu10-Am6 maintain the same, very low concentration of DO (around $2 \mathrm{mg} / \mathrm{L}$ ). On the other hand, treatments with lower amount of yucca (Yu0-Am0, Yu1-Am3) show a lower decrease rate and maintain DO concentrations of around 4 $\mathrm{mg} / \mathrm{L}$ and more.

Furthermore, all treatments, from 60 until 72 hours, had an increase in the concentration of DO, with the highest concentration observed in Yu0$\mathrm{Am} 0$ and $\mathrm{Yu} 1-\mathrm{Am} 3$ (approx. $6.5 \mathrm{mg} / \mathrm{L}$ ) and the lowest in Yu3-Am0 treatment $(2.2 \mathrm{mg} / \mathrm{L})$. From 72 hours onwards a gradient decrease of DO concentration for all treatments was recorded (Figure 1).

Therefore, it was noted that the treatments with a low or no amount of yucca had a lower decrease rate of DO concentration, which probably means that yucca extract, apart from ammonium, may also stimulate faster reduction of DO in the system.

Similar result was found in the research of Tidwell et al. [1992], who found that dissolved oxygen in fish tanks treated with yucca is much lower than other fish tanks. The reason why yucca reduces DO has not been studied yet. If applied to open water, DO might keep relatively constant since winds and mixing processes can circulate the lake water, bringing more oxygen to the deep-

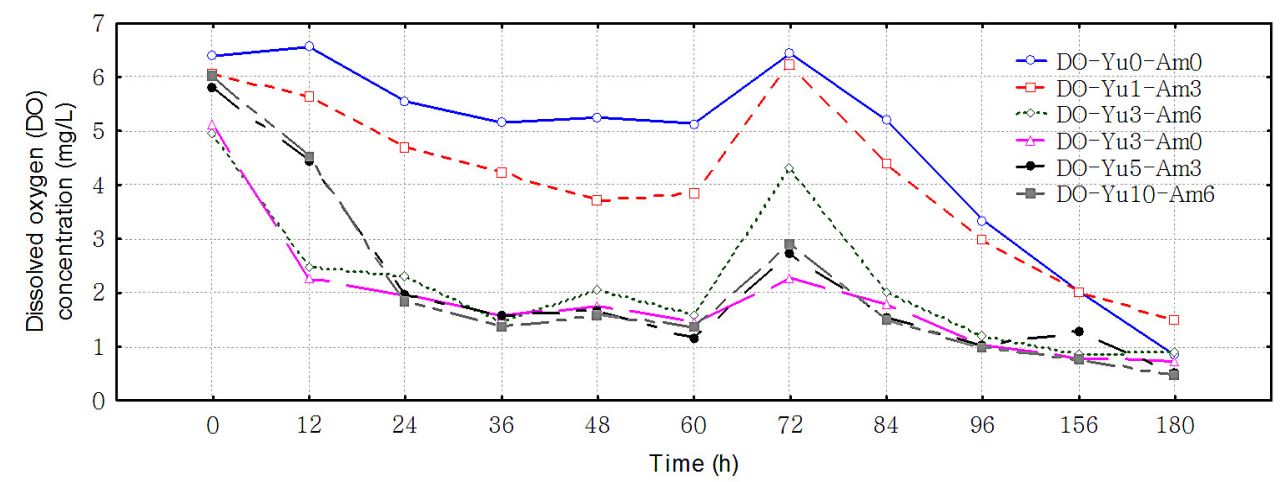

Figure 1. Change of DO of all treatments along time during the experiment 
er column. Wacharonke [1993] applied yucca extract in ponds with shrimp, with half of the pond aerated in the whole experiment period and the other half covered, and found that DO in ponds without aeration were extremely low while DO in aerated ponds was constant.

The initial value of $\mathrm{pH}$ in all the treatments was approximately 8 (Figure 2 ). As regards to the first 36 hours, a gradient decrease of $\mathrm{pH}$ values is observed in all treatments and the lowest $\mathrm{pH}$ levels were recorded in the Yu10-Am6 and Yu5Am3 treatments (5.3 and 6.3 respectively, Figure 2). The treatments that had the lowest Yucca content illustrated also the lower decrease in $\mathrm{pH}$ throughout the entire experiment period ( $\mathrm{Yu} 0-$ Am0, Yu1-Am3).

For the time period of 36 until 180 hours, a progressive increase of $\mathrm{pH}$ values on all treatments has been documented and at the end of the experimental process, $\mathrm{pH}$ returned approximately to its original levels.

\section{Effects of Yucca extract on ammonia and nitrate}

In Figure 3, concentration of ammonia nitrogen $(\mathrm{AN})(\mathrm{mg} / \mathrm{L})$ versus time $(\mathrm{h})$ for all six treatments is shown. Yu0-Am0 and Yu3-Am0 treatments do not appear to have any shift in am- monium nitrogen concentration during the entire experiment, as expected. The ammonium chloride solutions were introduced in all the treatments at the $24^{\text {th }}$ hour of the experiment which explains the respective peak of AN concentration in Figure 3. The initial measurements of AN in the tanks are slightly lower than the nominal concentrations expected after the addition of ammonium chloride but several processes can alter the measured concentrations in the tanks (reduction of AN from Yucca, nitrification processes, uptake by microalgae, etc.). For the period of 24-180 hours, a decrease on concentration of ammonium nitrogen for all treatments is noted, with the most significant ones for the Yu10Am6 and Yu5-Am3 (from 1.8 to $0 \mathrm{mg} / \mathrm{L}$ and from 1.2 to $0 \mathrm{mg} / \mathrm{L}$ respectively). These reductions in AN occurred within 24 hours while after that time (the $48^{\text {th }}$ hour) no significant changes were recorded in the Ammonia concentrations (remained close to zero until the end of the experiment). The Yu3-Am6 treatment illustrated an important AN reduction from $5.2 \mathrm{mg} / \mathrm{L}$ to 4 $\mathrm{mg} / \mathrm{L}$ but then the AN concentrations increased progressively again at the original levels (Figure 3). The Yu1-Am3 treatment illustrated a very slow and small reduction of AN concentrations from 2.6 to $2 \mathrm{mg} / \mathrm{L}$ which was achieved at the end of the experiment.

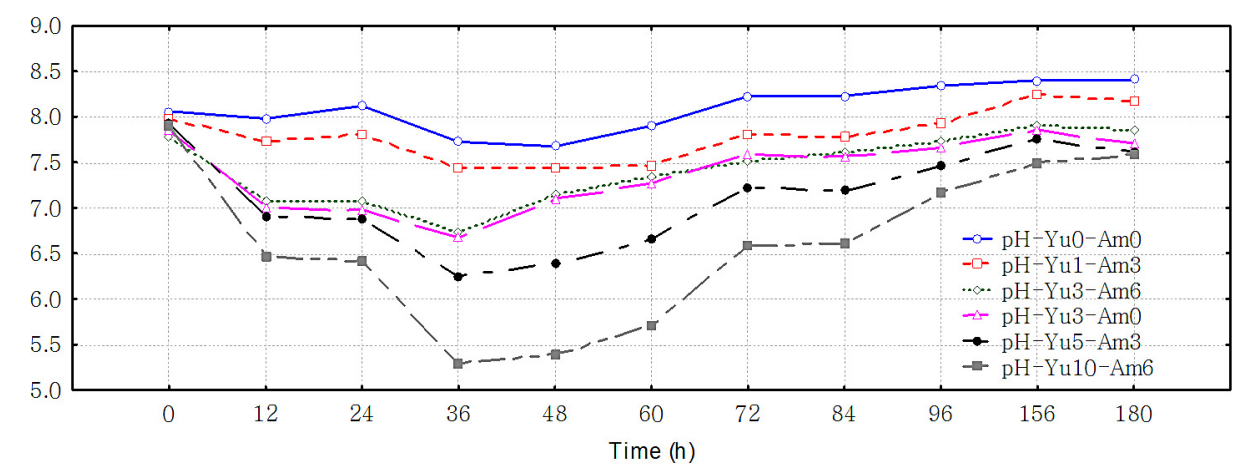

Figure 2. Change of $\mathrm{pH}$ of all treatments along time during the experiment

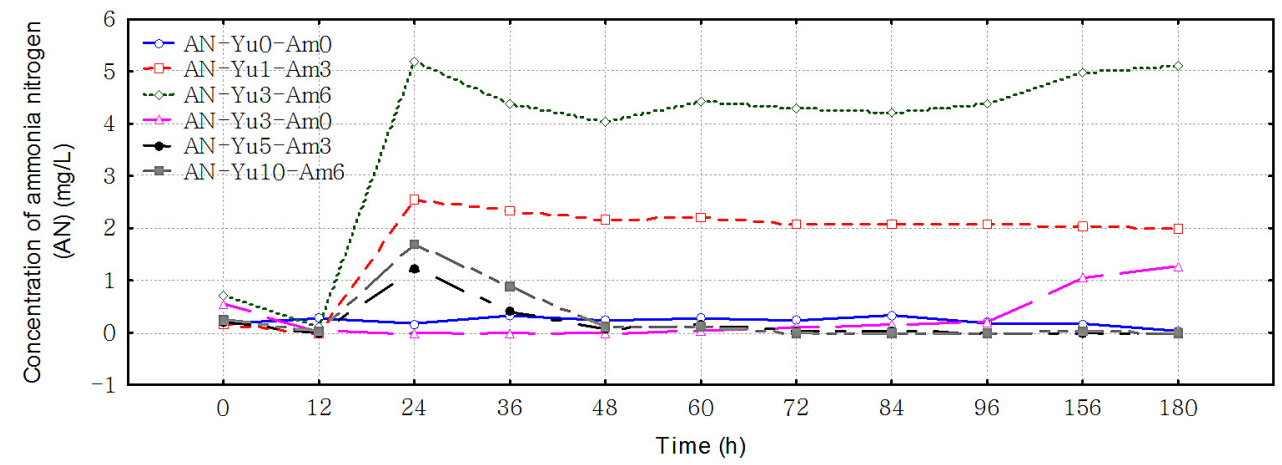

Figure 3. Change of ammonia nitrogen concentration of all treatments along time during the experiment 
Concentration of nitrate nitrogen $(\mathrm{NN})$ against time is described in Figure 4 for all treatments. Yu0-Am0 was constant throughout the experiment with concentration of NN close to zero, as expected. On the opposite, a steep increase was monitored for all the treatments with maximum peaks at the $12^{\text {th }}$ hour of the experiment for Yu3Am0 and Yu3-Am6 and maximum peaks at the $24^{\text {th }}$ hour for Yu1-Am3, Yu10-Am6 and Yu5-Am3 (figure 4). The highest concentrations of NN were observed in Yu10-Am6 (3.4 mg/L) and Yu5-Am3 (3.2 mg/L). Yu3-Am6, Yu1-Am3 and Yu3-Am0 appear to have imminent values of nitrate nitrogen concentration with a range of $0.9-1.2 \mathrm{mg} / \mathrm{L}$.

This significant increase in NN concentrations of all treatments in the first 12 hours of the experiment (before the addition of $\mathrm{AN}$ ) can be only assigned to the Yucca extract which is a plant extract and thus expected to contain nitrate values. This is validated by the fact that the highest the Yucca concentration in the treatment, the highest the NN values (Figure 4).

Continuing the experiment, a gradual decrease on $\mathrm{NN}$ concentration for all the treatments was presented with the largest decrease occurring until the $48^{\text {th }}$ hour of the experiment, especially for the treatments with high Yucca concentrations (Yu5-Am3 and Yu10-Am6). At the end of the ex- periment $\mathrm{NN}$ levels were fluctuating from 0 to 0.9 $\mathrm{mg} / \mathrm{L}$ in all treatments. This is probably due to intense denitrification process, which is favored by low DO level in the water [Hamrsley and Howes, 2002]. This process is also visible in the AN concentrations that illustrate a stabilization or a slight increase after the $36^{\text {th }}$ hour of the experiment.

The addition of yucca extract reduced the ammonia concentration in the lake water and the more yucca was added, the more AN was removed (correlation coefficient: 0.76, Figure 5). The greater AN reduction rates were achieved in treatments Yu10-Am6 and Yu5-Am3 (approximately $100 \%$ reduction in 24 hours) while the rest of the treatments illustrated limited or no reduction of ammonium whatsoever (Figure 5). This result indicates that Yucca concentrations of $2 \mathrm{ml} / \mathrm{L}$ is the best option for the efficient reduction of ammonium concentrations of approximately $6 \mathrm{mg} / \mathrm{L}$, even though it had significant side effects (reduced $\mathrm{pH}$ by $30 \%$ and DO by $66 \%$ ). Moreover, the application of $1 \mathrm{ml} / \mathrm{L}$ Yucca for ammonia concentrations of up to $6 \mathrm{mg} / \mathrm{L}$ also proved to be efficient and with lower side effects ( $20 \%$ reduction in $\mathrm{pH}$ ). Nevertheless, these side effects may not be of the same magnitude in real life applications since a lake ecosystem has natural mechanisms to balance and eliminate these adverse effects.

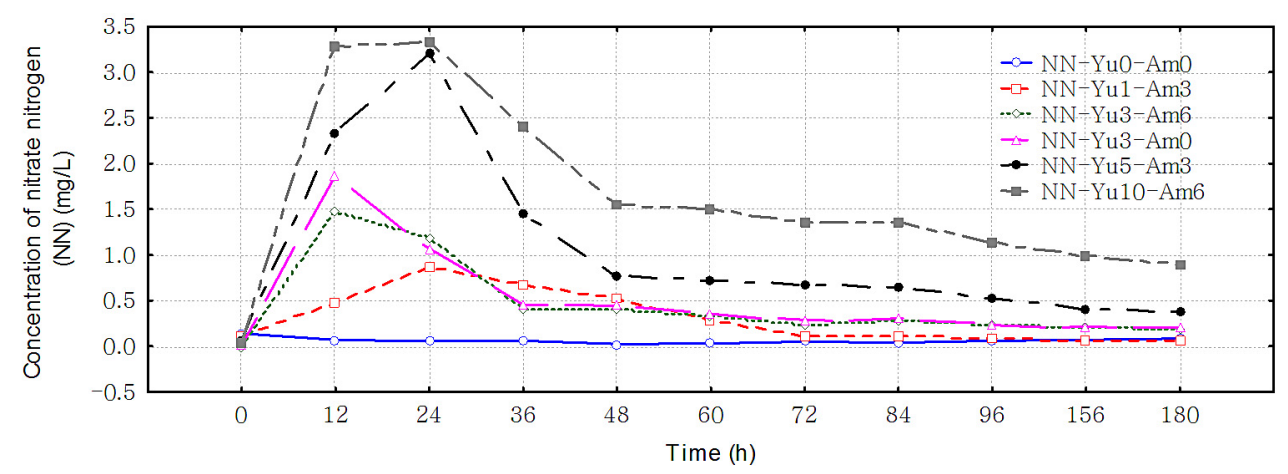

Figure 4. Change of nitrate nitrogen concentration of all treatments along time during the experiment

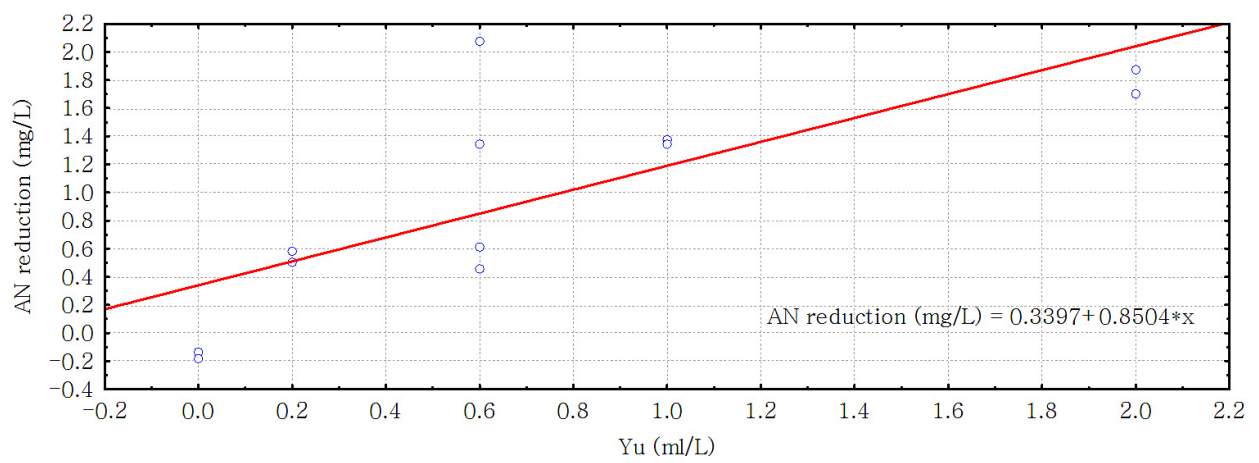

Figure 5. Linear relationship between the amount of yucca extract (Yu) added and the reduction of AN concentration during the experiment (Person correlation coefficient is 0.76 . Correlation is significant at $P<0.05$ ) 
Similar results have been found in previous studies. Wacharonke [1993] applied yucca extract in ponds with shrimp and found that yucca extract significantly reduced ammonia concentration and increased survival and growth rate of the shrimp. Santacruz-Reyes and Chien [2010a] applied yucca extract to freshwater with ammonia added and found that higher yucca concentration led to higher ammonia reduction, while ammonia reduction was highest at 12-24 $\mathrm{h}$ and decreased thereafter.

There are two theories of yucca extract acting on ammonia. One is that certain components in yucca convert ammonia to other forms of nitrogen [Headon and Dawson, 1990]. The other one is that saponin and glyco-components in yucca extract bind ammonia [Wacharonke, 1993; Santacruz-Reyes and Chien, 2010a]. In the present study the results indicate that Ammonia is probably bound in Yucca substances since the NN concentration fluctuations follow the AN concentration patterns and decrease simultaneously. Moreover, even though AN levels fall significantly in some treatments, the NN values do not get higher as expected but decrease as well (Figure 6). Therefore, there is no negative correlation between the AN and NN values in the present experiment which supports the Yucca-Ammonium binding approach.

While yucca extract is able to reduce ammonia in lake water, its component saponin is toxic to some aquatic species [Tidwell et al., 1992]. Saponins can change the permeability of cell wall and give rise to hemolysis, causing the malfunction of fish organs, especially gills [Tidwell et al., 1992]. However, Wacharonke [1993] sprayed 0.3 $\mathrm{mg} / \mathrm{L}$ yucca extract on the surface of pond with shrimp and found that growth and survival rate of shrimp was elevated, suggesting that yucca extract in low doses might not have negative effects to organisms. Nevertheless, further investigations on large-scale water bodies need to be conducted in order to assess the efficiency of Yucca in a real aquatic system and identify potential adverse effect in the biota. Some studies show that saponin can be removed from yucca extract without eliminating its capabilities of removing ammonia [Tidwell et al., 1992] which is something that also needs testing.

\section{CONCLUSIONS}

In the particular study, the extract of Yucca shidigera was tested in removing ammonia from Lake's Koumoundourou water and proved to be efficient. A concentration as low as $0.2 \mathrm{ml} / \mathrm{L}$ of Yucca can have a significant lowering impact on ammonia concentrations (100\% reduction when the levels of Ammonia are up to $1.2 \mathrm{mg} / \mathrm{L}$ ). The tendency identified in this study is that the more yucca extract is added, the more ammonia is removed and this has been statistically justified (correl. coefficient: 0.76).

Moreover, another advantage for the use of Yucca extract as a potential restoration measure is the relatively low cost associated with its application. Particularly, for a small lake such as Koumoundourou Lake, which has a volume of 150 million liters, according to the aforementioned experiment, $450 \mathrm{~kg}$ of yucca extract are necessary to be applied, which costs less than 1,000 euros.

However, there are potential adverse effects when large doses of Yucca are used, such as the decline of DO which needs to be compensated through water circulation and aeration (in some aquatic systems the natural water mixing processes may be adequate). Similar behavior is noted for $\mathrm{pH}$ values, where high amount of yucca extract

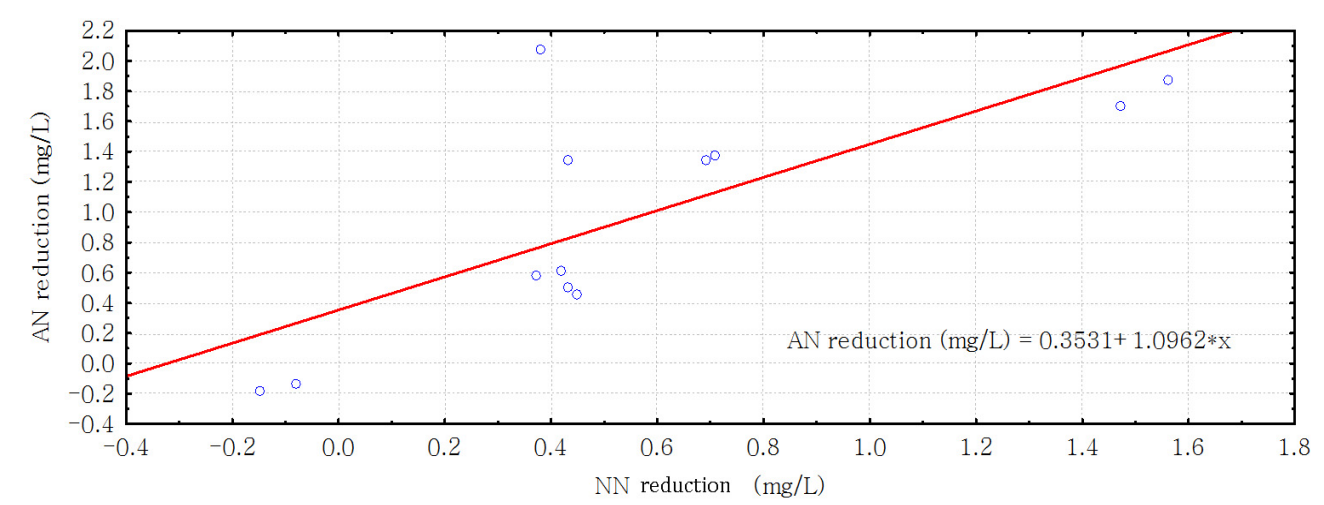

Fig. 6. Linear relationship between the increment of $\mathrm{NN}$ concentration and the reduction of AN concentration during the experiment (Pearson correlation coefficient is 0.75 . Correlation is significant at $P<0.05$ ) 
resulted in a significant decrease of $\mathrm{pH}$ values (up to $30 \%$ ). However, the aforementioned low dose of Yucca causes a lower decline of $\mathrm{pH}$ (approx. $20 \%$ ) which can be partially compensated by the relevant natural attenuation mechanisms of the aquatic systems.

It has been also observed that the amount of yucca extract added in the water body played a significant role for the concentration of nitratenitrogen. Particularly, a rapid increase in nitrate nitrogen concentration had been observed within the first few hours of the experiment due to the potential release of $\mathrm{NN}$ in the water from the yucca itself. This is an expected outcome due to the fact that Yucca is a plant extract and therefore contains NN. However, as time progresses the total dissolved nitrogen concentration gradually declines creating an overall positive effect for restoration purposes. Moreover, the effect of saponin components of Yucca on the biota of freshwater systems needs to be further investigated prior to any practical application. A macro-scale experiment should be organized, probably in a semiclosed part of Koumoundourou Lake to study the interactions between all the natural components and processes in combination to the Yucca treatment and assess the efficiency and potential impacts of this restoration technique.

\section{REFERENCES}

1. Burgess R.M., Perron M.M., Cantwell M.G., Ho K.T., Serbst J.R., Pelletier M.C. 2004. Use of zeolite for removing ammonia and ammonia-caused toxicity in marine toxicity identification evaluations. Arch. Environ. Contam. Toxicol. 47, 440-447.

2. Camargo J.A. and Alonso À. 2006. Ecological and toxicological effects of inorganic nitrogen pollution in aquatic ecosystems: a global assessment. Environment International 32, 831-849.

3. Demin O.A., Dudeney A.W.L., Tarasova I.I. 2002. Remediation of ammonia-rich minewater in constructed wetlands. Environmental Technology 23, 497-514.

4. Dimitriou E., Karaouzas I., Sarantakos K. Zacharias I., Bogdanos K., Diapoulis A. 2008. Ground- water risk assessment at a heavily industrialised catchment and the associated impacts on a periurban wetland. Journal of Environmental Management 88, 526-538.

5. Effler S.W., Brooks C.M., Auer M.T., Doerr S.M. 1990. Free ammonia and toxicity criteria in a polluted urban lake. Research Journal of the Water Pollution Control Federation 62, 771-779.

6. Hamrsley M.R. and Howes B.L. 2002. Control of denitrification in a septage-treating artificial wetland: The dual role of particulate organic carbon. Water Research 36, 4415-4427.

7. Headon D.R. and Dawson K.A. 1990. Yucca extract controls atmospheric ammonia levels. Feedstuffs $62,2-4$.

8. Hellenic Center for Marine Research. 2011. Assessment of chemical parameters (in Greek). http:// www.lake-koumoundourou.gr/upload_files/File/ chemical.pdf. (21.5.2012).

9. Koutsomitros S., Mimides T., Sgoumpopoulou A., Rizos S. 2001. Investigation of the self-cleaning ability of Lake Koumoundourou near Athens from oil pollution. Environ. Engg. And Policy 2, 155-159.

10. Lewis W.M. and Morris D.P. 1986. Toxicity of nitrite to fish: a review. Transactions of the American Fisheries Society 115, 183-195.

11. Santacruz-Reyes R.A. and Chien Y.-H. 2010a. Yucca schidigera extract - a bioresource for the reduction of ammonia from mariculture. Bioresource Technology 101, 5652-5657.

12. Santacruz-Reyes R.A. and Chien Y.-H. 2010b. Ammonia reduction in seawater by Yucca schidigera extract: efficacy analysis and empirical modelling. Aquaculture Res. 41, 1221-1228.

13. Tekeli A., Çelik L., Kutlu H.R. 2007. Plant extracts: a new rumen moderator in ruminant diets. Journal of Tekirdag Agricultural Faculty 4, 71-79.

14. Tidwell J.H., Webster C.D., Clark J.A., Yancey D.H. 1992. Effects of Yucca shidigera extract on water quality and fish growth in recirculatingwater aquaculture systems. The Progressive FishCulturist 54, 196-201.

15. Wacharonke C. 1993. Shrimp farming: a breakthrough in controlling nitrogen metabolism and minimizing water pollution. Alkech's 9th Annual Symposium on Biotechnotogy in the Feed Industry. 